\title{
Percaya Diri, Religiusitas dan Perilaku Menyontek
}

\author{
Evi Kusdiana ${ }^{1}$, M. As'ad Djalali², M. Farid ${ }^{3}$ \\ Fakultas Psikologi Universitas 17 Agustus 1945 Surabaya $^{1 \& 2}$, \\ Fakultas Psikologi Universitas Darul Ulum Jombang ${ }^{3}$ \\ Email: ephie.kusdiana@gmail.com ${ }^{1}$
}

\begin{abstract}
:
The cheating on exam attitude is a dishonest attitude. It can be done through copying, imitating, quoting, or duplicating the other student's essay/work to take the advantage in answering the questions of the exam.The aim of the research is to find out the correlation between self - confidence and religiousity toward the cheating on exam. The test of the instrument on the cheating attitude scale gives a result on 46 valid and reliable items. The subject of the research is 87 students by the technique of multistage cluster sampling. The data analysis technique used in the research is the double regression statistical analysis to examine the correlation between self-confidence and religousity with the cheating attitude, and the partial correlation technique to examine each independent variable toward the dependent one. Based on the calculation result using the regression statistical test, it shows that there is a negative correlation between self-confidence and religousity with the cheating attitude of the junior high school students $(F=20,398$ and $p=0,000: p<0,001)$. There is a significantly negative correlation between self-confidence and religousity with the cheating attitude $(p=0,024 ; p<0,05)$. There is a very significantly negative correlation between religousity and the cheating attitude $(p=0,000 ; p<0,01)$.
\end{abstract}

Keyword: Self-Confidence, Religousity, The Cheating Attitude

Received February 03, 2018; Revised March 05, 2018; Accepted April 01, 2018

How to Cite: Kusdiana E., Djalali M. A., \& Farid M. (2018). Percaya Diri, Religiusitas dan Perilaku Menyontek. JKI (Jurnal Konseling Indonesia), 3(2), 37-41.

This is an open access article distributed under the Creative Commons 4.0 Attribution License, which permits unrestricted use, distribution, and reproduction in any medium, provided the original work is properly cited. (2018 by author and Universitas Kanjuruhan Malang.

\section{PENDAHULUAN}

Pendidikan merupakan suatu upaya membentuk manusia yang berilmu dan berbudi pekerti yang baik (Gunawan, 2012). Untuk mewujudkan tujuan pendidikan nasional ini maka cara yang dapat ditempuh salah satunya dengan meningkatkan mutu atau kualitas pendidikan (Indonesia, 2003). Berbicara tentang mutu pendidikan tidak lepas dari sistem pendidikan yang diterapkan melalui kegiatan belajar-mengajar yang diselenggarakan sekolah. Sistem pendidikan di Indonesia yang menggunakan nilai tes sebagai bahan evaluasi belajar menyebabkan masyarakat berpikir bahwa prestasi belajar yang diraih hanya dari pencapaian nilai yang tinggi, bukan pada proses belajarnya.

Nilai Kriteria Ketuntasan Minimal (KKM) yang tinggi menjadikan siswa lebih fokus pada capaian nilai yang tinggi bukan pada ilmu. Siswa menganggap ujian sebagai alat penentu akan berhasil atau gagal dalam meraih peringkat, kenaikan kelas bahkan kelulusan, bukan instrumen yang dapat menunjukkan kemajuan 
dalam proses belajar. Karena itu segala cara dapat dilakukan, baik cara-cara positif maupun negatif dalam hal ini menyontek.

Beberapa penelitian mengenai perilaku menyontek menemukan beberapa faktor penyebab siswa menyontek. Seperti penelitian yang dilakukan (Nyamwange, Ondima, \& Onderi, 2013) faktor penyebab siswa menyontek antara lain: kurangnya persiapan menghadapi ulangan (32\%), persaingan yang ketat antara siswa $(13,8 \%)$ dan tekanan agar mendapatkan peringkat yang tinggi (21,6\%). Beberapa penelitian lainnya menyebutkan peran percaya diri dan religiusitas dalam hubungannya dengan perilaku menyontek. Percaya diri terbukti memiliki kontribusi terhadap perilaku menyontek (Raharjo \& Marwanto, 2015; Solagrasia, 2014). Adapun religiusitas juga memiliki hubungan negatif dengan perilaku menyontek. Semakin tinggi religiusitas seseorang maka semakin rendah perilaku menyontek (Silaen, 2015; Ula, 2014; Wairata, 2015).

\section{METODE PENELITIAN}

Penelitian korelasi ini menguji hubungan variabel bebas yaitu percaya diri dan religiusitas dengan variabel tergantung yaitu perilaku menyontek. Subyek penelitian adalah remaja berusia 12 hingga 15 tahun yang saat ini menempuh pendidikan Sekolah Menengah Pertama sebanyak 87 siswa. Pemilihan subyek dilakukan dengan teknik Multistage Cluster Sampling. Skala yang digunakan adalah skala percaya diri, religiusitas dan perilaku menyontek. Pengujian antar variabel menggunakan analisis regresi ganda dan analisis parsial.

\section{HASIL}

Hasil penghitungan statistik SPSS dengan teknik analisis regresi diperoleh $\mathrm{F}$ regresi $=20,398$ dengan $\mathrm{p}=0,000(\mathrm{p}<0,01)$. Temuan ini menunjukkan adanya korelasi sangat signifikan antara percaya diri dan religiusitas dengan perilaku menyontek siswa. Dengan demikian hipotesis pertama yang menyatakan ada hubungan antara percaya diri dan religiusitas dengan perilaku menyontek diterima. Besar sumbangan percaya diri dan religiusitas terhadap perilaku menyontek secara bersama-sama diperoleh R Square sebesar 0,327 , berarti sumbangan efektif percaya diri dan religiusitas secara bersama-sama sebesar $32,7 \%$. Ini menunjukkan bahwa masih ada $67,3 \%$ perilaku menyontek siswa dipengaruhi oleh variabel atau faktor lain.

Hasil analisis parsial (komputasi dengan menggunakan program SPSS 20.0, ditemukan $\mathrm{t}=-2,301$ dengan $\mathrm{p}=0,024(\mathrm{p}<0,05)$. Temuan ini menunjukkan adanya korelasi negatif signifikan antara percaya diri dengan perilaku menyontek siswa. Semakin tinggi percaya diri siswa maka semakin rendah perilaku menyontek. Sebaliknya, semakin rendah percaya diri siswa maka semakin tinggi perilaku menyontek. Dengan demikian hipotesis yang menyatakan ada hubungan negatif antara percaya diri dengan perilaku menyontek diterima.

Hasil analisis parsial (komputasi dengan menggunakan program SPSS 20.0, ditemukan $\mathrm{t}=-5,545$ dengan $\mathrm{p}=0,000(\mathrm{p}<0,01)$. Temuan ini menunjukkan adanya korelasi negatif sangat signifikan antara religiusitas dengan perilaku menyontek siswa. Semakin tinggi religiusitas siswa maka semakin rendah perilaku menyontek. Sebaliknya, semakin rendah religiusitas siswa maka semakin tinggi perilaku menyontek. Dengan demikian hipotesis yang menyatakan ada hubungan negatif antara religiusitas dengan perilaku menyontek diterima.

Sebagian besar reponden dalam penelitian ini berada pada tingkat perilaku menyontek yang rendah (gambar 1), tingkat percaya diri responden sebagian besar berada pada area tinggi (gambar 2) dan tingkat religiusitas berada pada kategori sangat tinggi (gambar 3).

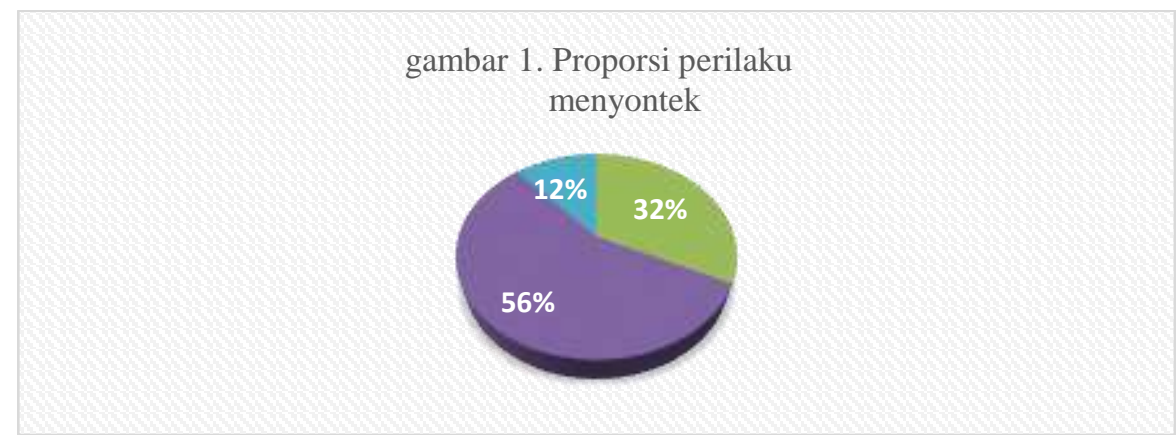



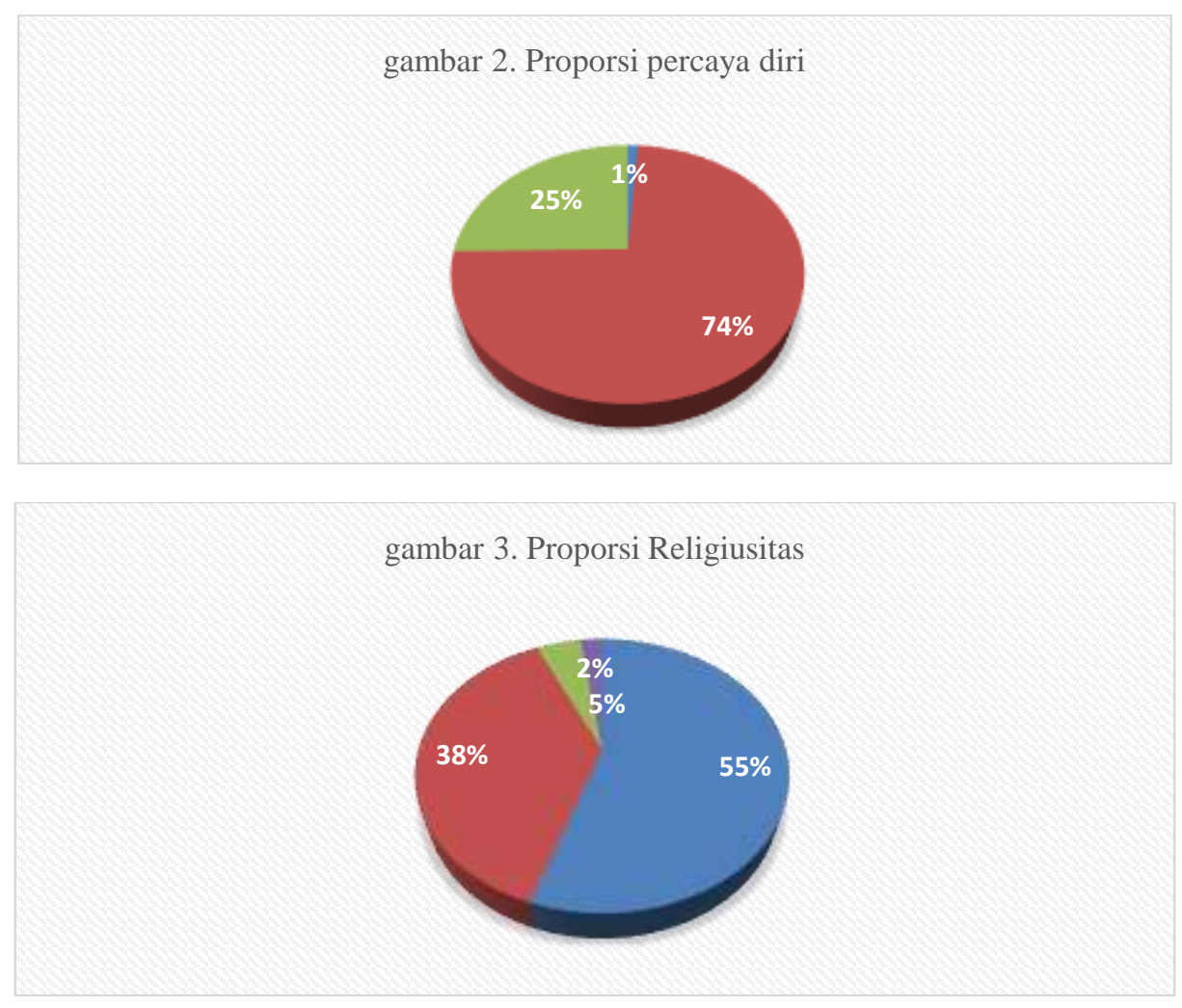

\section{PEMBAHASAN}

Dari hasil temuan penelitian di atas didapatkan hasil penghitungan statistik SPSS versi 20.00 dengan teknik analisis regresi diperoleh signifikansi 0,000 berada pada taraf di bawah 0,05 , artinya percaya diri dan religiusitas secara bersama-sama berkorelasi dan memiliki prediksi negatif terhadap perilaku menyontek siswa. Semakin tinggi percaya diri dan religiusitas siswa semakin rendah perilaku menyontek. Demikian pula sebaliknya, semakin rendah percaya diri dan religiusitas seseorang maka semakin tinggi perilaku menyontek. Hal tersebut sejalan dengan hipotesis mayor yang diajukan bahwa percaya diri dan religiusitas secara bersama-sama berpengaruh terhadap perilaku menyontek siswa.

Hipotesis kedua yang berbunyi, ada hubungan antara percaya diri dengan perilaku menyontek juga diterima karena berdasarkan hasil analisis parsial ada hubungan negatif yang signifikan antara percaya diri dengan perilaku menyontek. Semakin tinggi percaya diri seseorang semakin rendah perilaku menyontek. Kepercayaan diri memberikan kontribusi terhadap penurunan perilaku menyontek siswa. Pandangan positif terhadap keadaan diri dan merasa yakin dengan kemampuan yang dimiliki, dapat menimbulkan rasa percaya diri yang tinggi. Kepercayaan diri yang baik, segala perilakunya akan selalu tertuju pada keberhasilan.

Kepercayaan diri siswa dapat tercapai apabila ada kesadaran dari siswa itu sendiri maupun faktor dari luar dirinya bahwa kepercayaan diri menimbulkan dampak yang baik dalam kegiatan pembelajaran. Faktorfaktor yang mempengaruhi tinggi rendahnya percaya diri seseorang antara lain: konsep diri, harga diri, pengalaman dan pendidikan (Ghufron \& Wita, n.d.)

Hipotesis ketiga yaitu, ada hubungan antara religiusitas dengan perilaku menyontek diterima. Hasil tersebut menunjukkan bahwa ternyata religiusitas mempunyai peran penting dalam perilaku menyontek. Pola hubungan yang negatif menunnjukkan bahwa semakin tinggi nilai religiusitas seseorang maka akan semakin kecil kemungkinan untuk menyontek.

Religiusitas adalah pemahaman untuk melakukan dan mengikuti prnsip-prinsip agama. Sebagai contoh dalam agama islam, seorang muslim, diperintahkan untuk menaaati perintah agama baik dalam hal sikap, perkataan dan perbuatannya (Ancok, Suroso, \& Ardani, 2000). Pada saat seseorang memasukkan dimensidimensi agama dalam kehidupannya, maka pengalaman-pengalaman individual yang dialami akan mempengaruhinya untuk menjaga perkataan dan perilakunya, serta mencegah dari perbuatan yang melanggar kaidah agama. 
Siswa yang menerapkan nilai-nilai religiusitas tahu batasan mana yang baik, boleh dan berpahala, tahu bahwa dirinya selalu dalam pengawasan Tuhan sedangkan siswa yang tidak memiliki nilai-religiusitas tidak akan merasa takut berbuat dosa ataupun takut dilihat Tuhan. Sumbangan efektif percaya diri dan religiusitas secara bersama-sama terhadap perilaku menyontek sebesar 32,7\%. Ini berarti masih ada 67,3\% faktor lain yang mempengaruhi perilaku menyontek.

\section{SIMPULAN DAN SARAN}

\section{Simpulan}

Perilaku menyontek semakin meningkat dan dialami hampir seluruh wilayah di Indonesia apalagi selama pelaksanaan ujian nasional. Sedangkan faktor penyebab siswa menyontek beragam, dalam beberapa penelitian diperoleh hasil: (1) kurangnya persiapan menghadapi ulangan, (2) persaingan yang ketat antara siswa dan (3) tekanan agar mendapatkan peringkat yang tinggi, (4) adanya kesempatan terjadinya perilaku, (5) konsep diri yang salah terlepas dari beragama apapun, (6) lingkungan dan contoh atau model terdekat, (7) kurangnya percaya diri dan lain sebagainya.

Penelitian ini dilakukan dengan memilh variabel perilaku menyontek sebagai variabel dependent sedangkan percaya diri dan religiusitas sebagai variabel independen. Subjek penelitian ini adalah siswa SMP Negeri 1 Tlanakan sebanyak 87 siswa. Pemilihan subjek secara Multistage Cluster Sampling dengan cara random.

Analisis data penelitian ini dilakukan dengan menggunakan analisis regresi ganda. Hasil analisis regresi sebagai berikut: ada hubungan secara bersama-sama antara percaya diri dan religiusitas denga $\mathrm{n}$ perilaku menyontek. Hasil korelasi parsial menunjukkan ada hubungan negatif antara percaya diri dengan perilaku menyontek dan ada hubungan negatif antara religiusitas dengan perilaku menyontek. Koefisien korelasi yang negatif antara variabel percaya diri dengan perilaku menyontek menunjukkan semakin tinggi percaya diri siswa maka semakin rendah perilaku menyontek, begitu pula sebaliknya. Nilai koefisien korelasi yang sama juga terjadi pada variabel religiusitas dengan perilaku menyontek, semakin tinggi religiusitas siswa maka semakin rendah perilaku menyonteknya.

\section{Saran}

1. Bagi siswa, diharapkan untuk bisa meningkatkan rasa percaya diri melalui kegiatan-kegiatan pengembangan diri dengan memanfaatkan kegiatan ekstrakurikuler di sekolah yang sesuai dengan bakat dan minat ataupun melibatkan diri dalam kegiatan positif lainnya yang ada di masyarakat.

2. Bagi orang tua, perlu peran orang tua dalam upaya menanamkan percaya diri dengan menghargai setiap usaha dan hasil yang diraih anak serta mendukung anak untuk mengembangkan potensi yang dimiliki. Religiusitas pada anak juga perlu dibimbing dan ditingkatkan dalam mengembangkan sikap jujur dan mengedepankan norma-norma agama, baik dalam keseharian anak maupun proses pembelajaran.

3. Pihak sekolah dapat menyediakan wadah dan memberikan kesempatan bagi siswa untuk mengembangkan potensinya melalui kegiatan ekstrakurikuler. Mengembangkan potensi diri dapat meningkatkan percaya diri. Peningkatan percaya diri juga dapat dilakukan oleh guru BK melalui kegiatan bimbingan kelompok. Kegiatan yang berhubungan dengan religiusitas dapat dilakukan dengan melaksanakan ibadah bersama setiap pagi dan siang hari dan mengadakan kajian keagamaan di tiap-tiap kelas, agar dalam diri siswa tertanam sikap menghargai diri sendiri dan jujur dalam setiap kegiatan belajar mengajar.

4. Peneliti selanjutnya dapat mempertimbangkan variabel percaya diri dan religiusitas terhadap perilaku menyontek pada ruang lingkup yang lebih luas, jumlah responden yang lebih banyak dan metode penelitian yang lebih akurat seperti eksperimen.

\section{DAFTAR RUJUKAN}

Ancok, D., Suroso, F. N., \& Ardani, M. S. (2000). Psikologi islami: Solusi islam atas problem-problem psikologi. Pustaka Pelajar.

Ghufron, M. N., \& Wita, R. R. (n.d.). S.(2011). Teori-Teori Psikologi. Jogjakarta: Ar-Ruz Media.

Gunawan, H. (2012). Pendidikan Karakter. Bandung: Alfabeta.

Indonesia, U.-U. R. (2003). Sistem Pendidikan Nasional. Jakarta: Direktorat Pendidikan Menengah Umum. Nyamwange, C., Ondima, P., \& Onderi, P. (2013). Factors Influencing Examination Cheating Among 
Secondary School Students: A Case of Masaba South District of Kisii County. Elixir Psychology, 56, 13519-13524.

Raharjo, P. G. P., \& Marwanto, A. (2015). PENGARUH KEPERCAYAAN DIRI DAN KONFORMITAS TEMAN SEBAYA TERHADAP PERILAKU MENYONTEK SISWA KELAS XI JURUSAN

TEKNIK PENGELASAN. Jurnal Pendidikan Vokasional Teknik Mesin, 3(4), 255-262.

Silaen, D. (2015). Hubungan Religiusitas Dengan Intensi Menyontek Pada Mahasiswa Kristen Protestan Universitas Padjadjaran Jatinangor. Universitas Padjadjaran.

Solagrasia, K. (2014). Perilaku Menyontek pada Siswa Ditinjau dari Kepercayaan Diri dan Strategi Coping. TALENTA, 3(2).

Ula, A. H. (2014). Hubungan antara efikasi diri dan religiusitas dengan intensitas perilaku menyontek pada siswa di MTs Mazra'atul Ulum Paciran Lamongan. Universitas Islan Negeri Maulana Malik Ibrahim.

Wairata, N. (2015). Hubungan antara Tingkat Religiusitas dengan Perilaku Menyontek Siswa SMK T\&I Kristen Salatiga. Program Studi Psikologi FPSI-UKSW. 